International Journal on Cybernetics \& Informatics (IJCI) Vol. 5, No. 4, August 2016

\title{
Performance Analysis Of CRT For Image ENCRYPTION
}

\author{
Dr.O.Srinivasa Rao \\ Department of Computer Engineering, UCEK, JNTUK ,Kakinada
}

\begin{abstract}
With the fast advancements of information technology, the security of image data transmitted or stored over internet is become very difficult. To hide the details, an effective method is encryption, so that only authorized persons can decrypt the image with the keys available. Since the default features of digital image such as high capacity data, large redundancy and large similarities among pixels, the conventional encryption algorithms such as AES, , DES, 3DES, and Blow Fish, are not applicable for real time image encryption. This paper presents the performance of CRT for image encryption to secure storage and transmission of image over internet.
\end{abstract}

\section{KEYWORDS}

Digital image, Chinese Remainder Theorem, encryption, confidentiality

\section{INTRODUCTION}

The role of Digital images is important, both in daily life applications as well as in areas of research and technology. An image is a 2-D representation of a three dimensional scene. Due to its large capacity data, huge redundancy and high similarities among pixels, there are several researchers [1-7] done lot of work for image compression for long period except for image encryption, From this, research papers we see that the compression performances are good.

Many number of image encryption schemes combined with compression are proposed. These methods divide the image encryption and image compression into two separate stages [8-13]. These, mainly separate the encryption without considering the compression process. Few propose overcome the drawbacks in Refs. [8-13] by making the image encryption and compression in a single process [14-17]. Refs [18] propose a new image encryption algorithm integrated with compression using 2D hyper-chaos discrete nonlinear dynamic system and Chinese remainder theorem. However these papers do not evaluate the performance of CRT. This paper presents the optimal performance and limitations of CRT for image compression.

\section{Chinese Remainder TheOREM}

Chinese remainder theorem [19-23] is a theorem about congruence's in number theory. It can be stated as follows:

If $\mathrm{m}_{1}, \mathrm{~m}_{2}, \ldots . . \mathrm{m}_{\mathrm{k}}$ are pair-wise relatively prime positive integers , and if $\mathrm{a}_{1}, \mathrm{a}_{2}, \ldots, \mathrm{a}_{\mathrm{k}}$ are any integers, then the simultaneous congruence's 
$x \equiv \mathrm{a}_{1}\left(\bmod \mathrm{m}_{1}\right), x \equiv \mathrm{a}_{2}\left(\bmod \mathrm{m}_{2}\right), \ldots, x \equiv \mathrm{a}_{\mathrm{k}}\left(\bmod \mathrm{m}_{\mathrm{k}}\right)$ have a solution, and the solution is unique modulo $\mathrm{m}$, where $\mathrm{m}=\mathrm{m}_{1} \mathrm{~m}_{2} \ldots \mathrm{m}_{\mathrm{k}}$

From Chinese remainder theorem, using $\mathrm{k}$ gray values, $\mathrm{a}_{1}, \mathrm{a}_{2}, \ldots ., \mathrm{a}_{\mathrm{k}}$, we get a gray value: $x \equiv m_{1} m_{1}^{-1} a_{1}+m_{2} m_{2}^{-1} a_{2}+\cdots+m_{k} m_{k}^{-1} a_{k}(\bmod m)$. Therefore. CRT can encrypt an image, at the same it also compress the image with a given compression ratio $\mathrm{k}$, simultaneously. From the unique solution $x \equiv m_{1} m_{1}^{-1} a_{1}+m_{2} m_{2}^{-1} a_{2}+\cdots+m_{k} m_{k}^{-1} a_{k}(\bmod m)$. we can also get $a_{\mathrm{i}}$ by $\mathrm{a}_{\mathrm{i}} \equiv \mathrm{x}\left(\bmod \mathrm{m}_{\mathrm{i}}\right)$, where $\mathrm{i}=1, \ldots, \mathrm{k}$. The above procedure is used for decryption and to uncompress the image.

The Chinese Remainder Theorem can be used for generating Godel numbering for sequences, for Good Thomas Fast Fourier transforms for re-indexing of data, for implementing the RSA encryption and decryption, for distributing the shared key among a group of people, and also used for range ambiguity resolution techniques with medium pulse repetition frequency radar Some of the important parameters image are PSNR value and Correlations are define as follows

\section{PSNR value}

Peak signal-to-noise ratio, often abbreviated PSNR, is the ratio between the maximum possible power of a signal and the power of corrupting noise that affects the fidelity of its representation. PSNR is usually expressed in terms of the logarithmic decibel scale.

$$
\begin{aligned}
\text { PSNR } & =10 \cdot \log _{10}\left(\frac{M A X_{I}^{2}}{M S E}\right) \\
& =20 \cdot \log _{10}\left(\frac{M A X_{I}}{\sqrt{M S E}}\right) \\
& =20 \cdot \log _{10}\left(M A X_{I}\right)-10 \cdot \log _{10}(M S E)
\end{aligned}
$$

\section{Correlation}

Correlation coefficient is a coefficient that illustrates a quantitative measure of some type of correlation and dependence, meaning statistical relationships between two or more random variables or observed data values.

\section{IMAge EnCRYPTION Procedure USING CRT}

Step1: To compress an image with size $\mathrm{HxW}$ in to an image with size $(\mathrm{HxW}) / \mathrm{K}$, we , set compression ratio $\mathrm{k}$. This compression ration $\mathrm{k}$ is achieved by selecting randomly $\mathrm{K}$ integers: $\mathrm{a}_{1}, \mathrm{a}_{2}, \ldots \ldots . . \mathrm{ak}, \mathrm{a}_{\mathrm{i}}$, where $\mathrm{a}_{\mathrm{i}}>256, \mathrm{gcd}\left(\mathrm{a}_{\mathrm{i}}, \mathrm{a}_{\mathrm{j}}\right)=1,1<=\mathrm{i}, \mathrm{j}<=\mathrm{k}$, where $\mathrm{H}$ and $\mathrm{W}$ are the height and width of the plain image

Step2: Divide the shuffled gray value sequence $S^{\prime}$ into

$$
\begin{gathered}
(\mathrm{H} \mathrm{xW}) / \mathrm{k} \text { blocks: } B_{1}=\left\{S_{1}^{l}, S_{2}^{I}, \ldots \ldots, S_{k}^{I}\right\}, B_{2}=\left\{S_{k+1}^{l}, S_{k+2}^{l}, \ldots \ldots, S_{2 k}^{l}\right\}, \ldots \ldots \ldots, \\
B_{(H X W) / k}=\left\{S_{H X W-(k-1)}^{I}, S_{H W W-(k-2)}^{I}, \ldots, S_{H x W}^{I}\right.
\end{gathered}
$$


Step3: For each block Bi, i=1, 2, . , $(\mathrm{H} \mathrm{x} \mathrm{W}) / \mathrm{k}$, by using CRT formula, encrypt each block into a value $\mathrm{Vi}$, and get the encrypted and compressed sequence $\mathrm{V}=\left\{\mathrm{V} 1, \mathrm{~V} 2, \ldots, \mathrm{V}_{(\mathrm{HxW}) / \mathrm{K}}\right\}$. Note that for each block $\mathrm{Bi}, \mathrm{x}_{1}, \mathrm{x}_{2}, \ldots, \mathrm{x}_{\mathrm{k}}$ can be different, which may enhance the security of the algorithm Step4: To form the encrypted and compressed image, reshape $\mathrm{V}$ back to the $2 \mathrm{D}$ value matrix with size $(\mathrm{H} \times \mathrm{W}) / \mathrm{k}$

For experimental purpose, as example, I take $\mathrm{k}=4$. This means that the cipher image is compressed into $1 / 4$ of the plain image and further $I$ chosen $\mathrm{m}_{1}=311, \mathrm{~m}_{2}=313, \mathrm{~m}_{3}=317, \mathrm{~m}_{4}=293$ randomly for encryption and decryption

The following procedure is used to uncompress and decrypt the image:

Step1: Arrange the encrypted-compressed image into a sequence

$$
\mathrm{V}=\left\{\mathrm{V} 1, \mathrm{~V} 2, \ldots, \mathrm{V}_{(\mathrm{HXw}) / \mathrm{K}}\right\}
$$

Step2: Decrypt each Vi into $k$ integers $x_{1}, x_{2}, \ldots, x_{k}$ by $x_{j}=V_{i}\left(\bmod m_{j}\right), j=1,2, \ldots, k$,

where $m_{i}$ is defined in the encryption procedure. Then, get a decrypted sequence $\mathrm{X}=\left\{\mathrm{x}_{1}, \mathrm{X}_{2}, \ldots, \mathrm{x}_{(\mathrm{HxW})}\right\}$.

Step3: Reshape $\mathrm{X}=\left\{\mathrm{x}_{1}, \mathrm{x}_{2}, \ldots, \mathrm{x}_{(\mathrm{HxW})}\right\}$ values with $\mathrm{H}$ rows and $\mathrm{W}$ columns to form the decrypted and decompressed image.

\section{RESUlt AND ANALYSIS}

The following results shows the histograms of original, encrypted and decrypted image along with the correlation for different key values of the following standard image

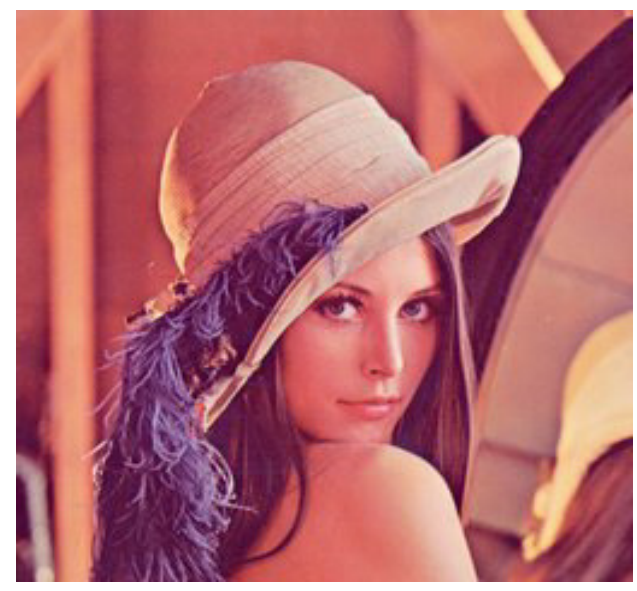

Standard .jpg

\section{Key Values used are:}

$\mathrm{m}=[467] ; \quad \mathrm{m}$ for $\mathrm{a}=1$

$\mathrm{m}=[971977] ;$ for $\mathrm{a}=2$

$\mathrm{m}=\left[\begin{array}{ll}263269271\end{array}\right] ; \quad$ for $\mathrm{a}=3$ 
International Journal on Cybernetics \& Informatics (IJCI) Vol. 5, No. 4, August 2016

$$
\begin{aligned}
& \mathrm{m}=[977983991997] ; \quad \text { for } \mathrm{a}=4
\end{aligned}
$$

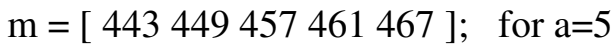

$$
\begin{aligned}
& \mathrm{m}=\left[\begin{array}{lllll}
263 & 269271277281283
\end{array}\right] ; \quad \text { for } \mathrm{a}=6 \\
& \mathrm{~m}=\left[\begin{array}{lllllll}
257 & 263 & 269 & 271 & 277 & 281 & 283
\end{array}\right] ; \quad \text { for } \mathrm{a}=7 \\
& \mathrm{~m}=\left[\begin{array}{llllllll}
307 & 311 & 313 & 317 & 331 & 337 & 347 & 349
\end{array}\right] ; \quad \text { for } \mathrm{a}=8 \\
& \mathrm{~m}=\left[\begin{array}{lllllllll}
257 & 263 & 269 & 271 & 277 & 281 & 283 & 293 & 307
\end{array}\right] ; \quad \text { for } \mathrm{a}=9 \\
& \mathrm{~m}=\left[\begin{array}{llllllllll}
257 & 263 & 269 & 271 & 277 & 281 & 283 & 293 & 307 & 311
\end{array}\right] ; \quad \text { for } \mathrm{a}=10
\end{aligned}
$$

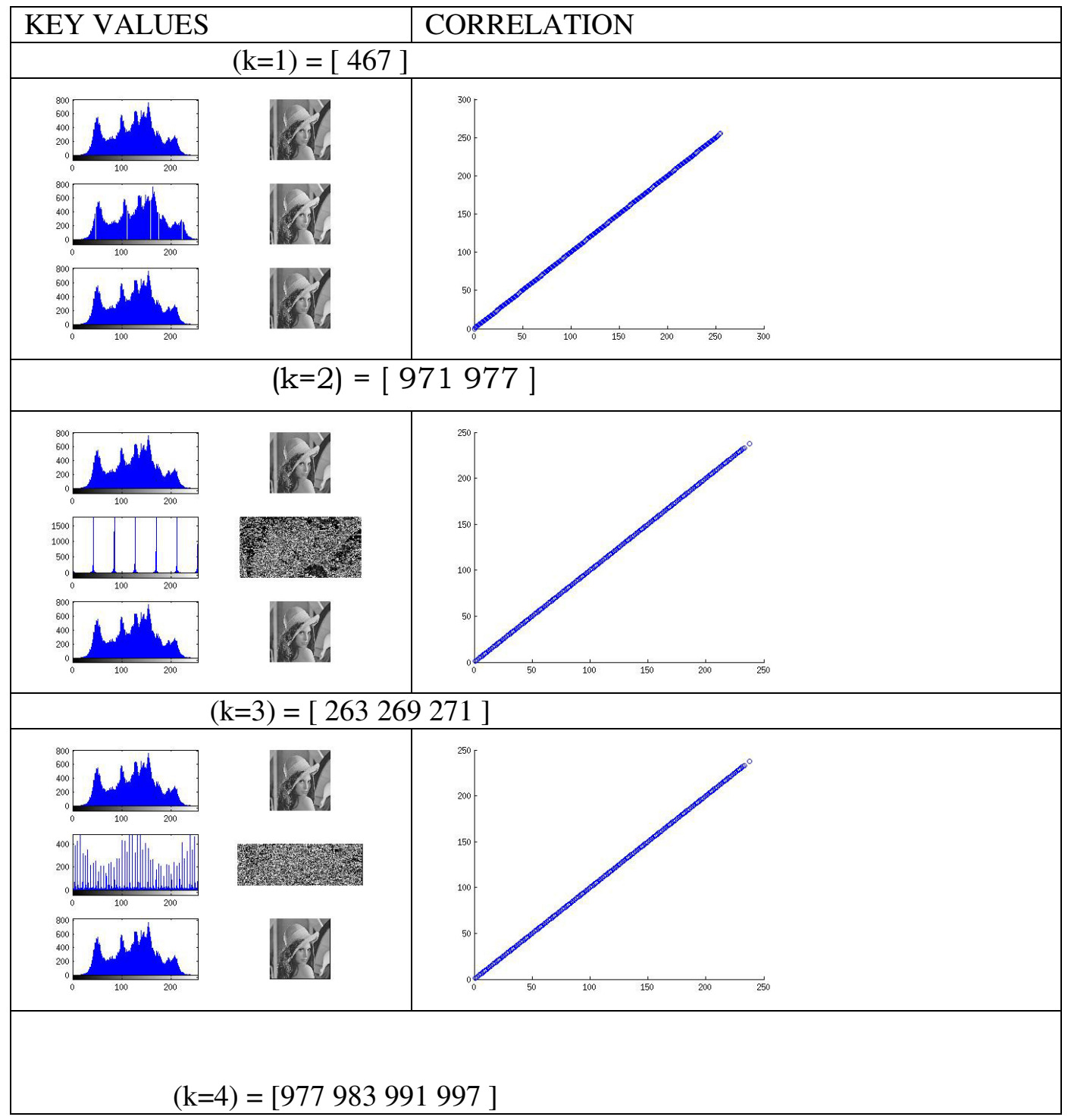


International Journal on Cybernetics \& Informatics (IJCI) Vol. 5, No. 4, August 2016

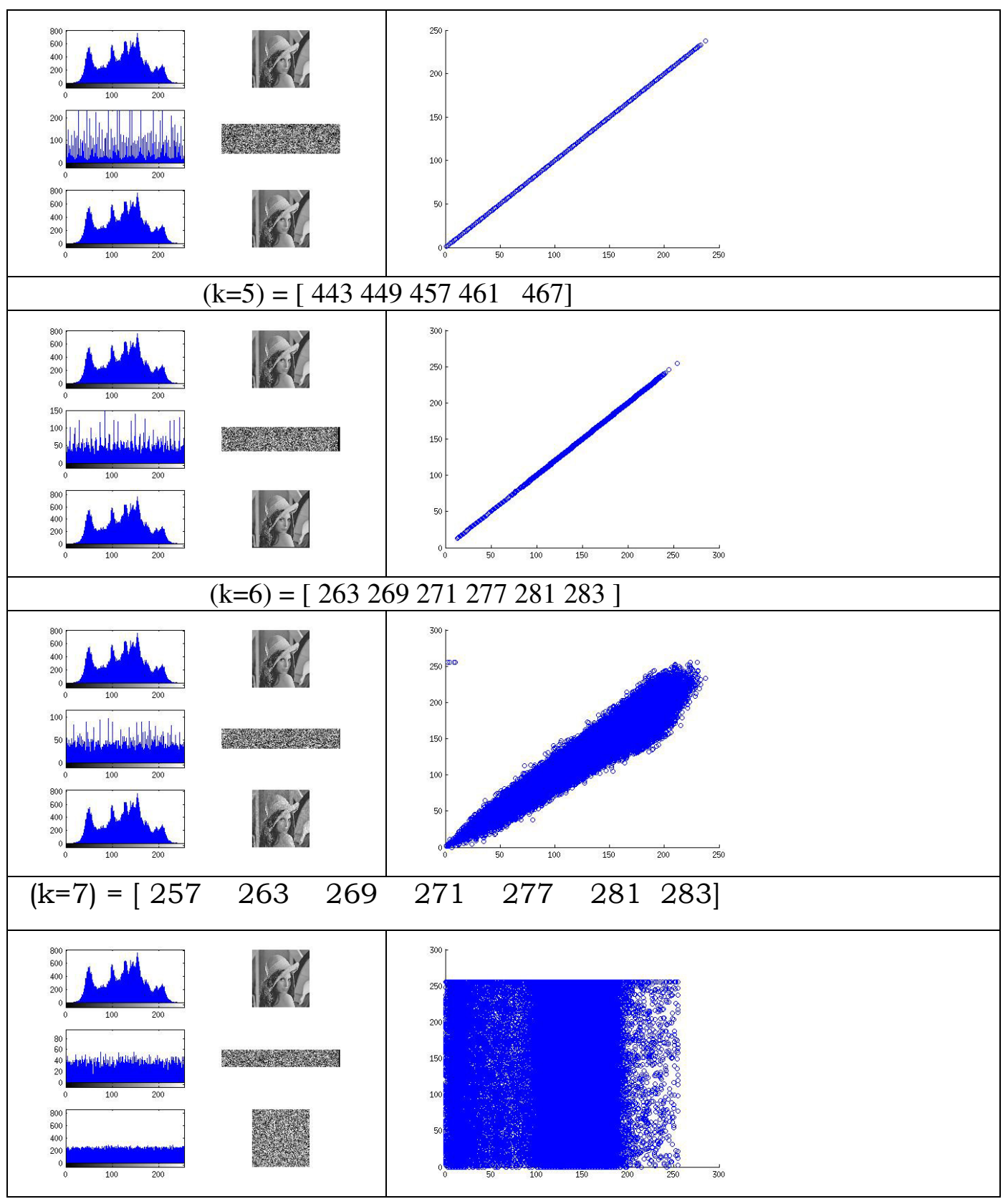


International Journal on Cybernetics \& Informatics (IJCI) Vol. 5, No. 4, August 2016

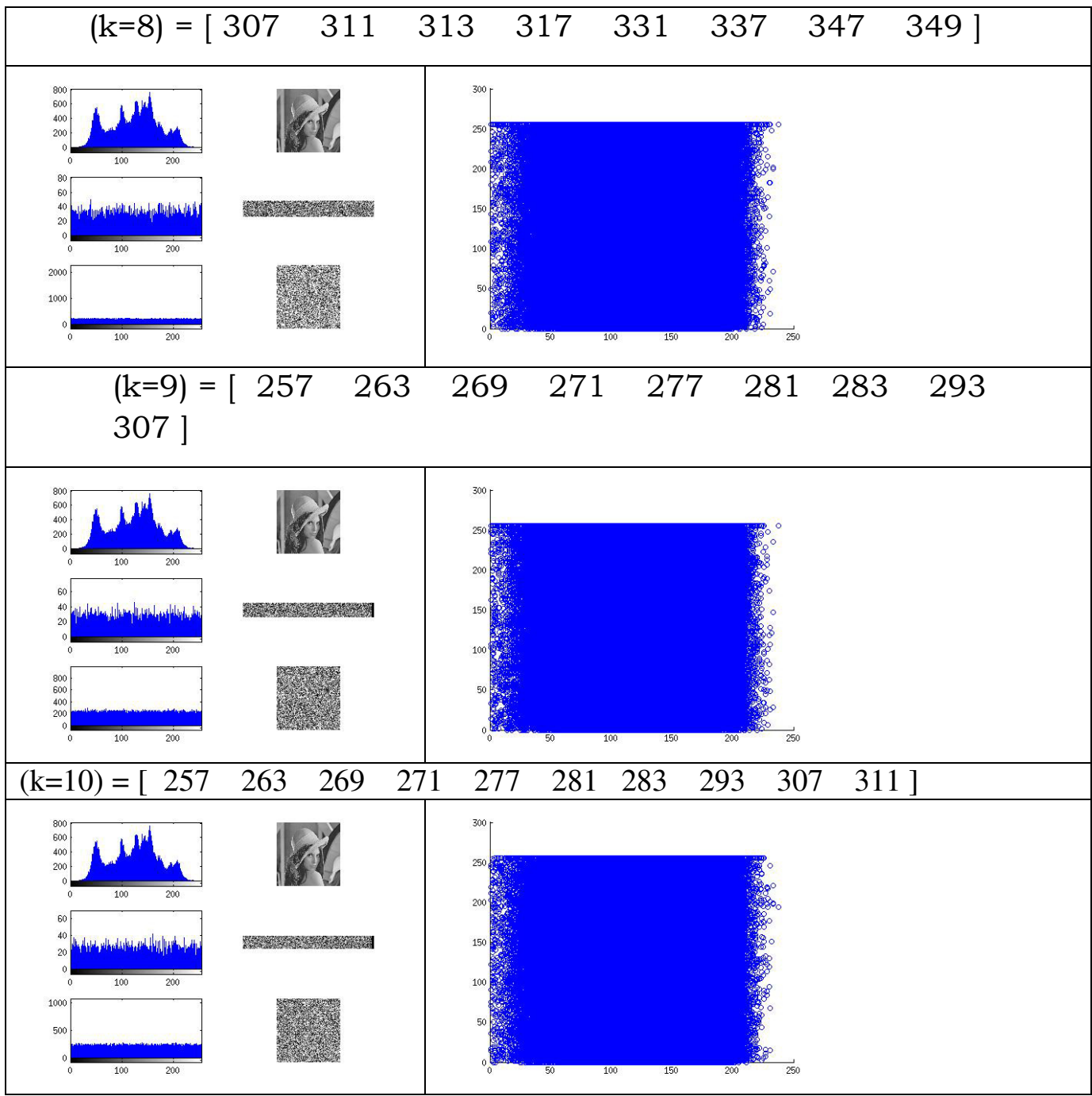

\section{ANALYSIS}

The following table values of correlation coefficient, PSNR and MSE for the sample image to the number of keys

\begin{tabular}{|c|c|c|c|}
\hline SAMPLE NAME & $\begin{array}{l}\text { Correlation } \\
\text { coefficient }\end{array}$ & PSNR value & MSE value \\
\hline Number of Keys $=1, m=[467]$ & 1 & infinity & 0 \\
\hline Number of keys $=2 ; m=[971977]$ & 1 & infinity & 0 \\
\hline Number of keys= 3, $m=\left[\begin{array}{lll}263 & 269 & 271\end{array}\right]$ & 1 & infinity & 0 \\
\hline Number of keys= 4, m = [977983991997 ] & 1 & infinity & 0 \\
\hline Number of keys= 5, $m=\left[\begin{array}{lll}443449457461467\end{array}\right]$ & 1 & Infinity & 0 \\
\hline
\end{tabular}


International Journal on Cybernetics \& Informatics (IJCI) Vol. 5, No. 4, August 2016

\begin{tabular}{|c|c|c|c|c|c|c|c|}
\hline Number of keys $=6, m=[263$ & 2692 & 71277 & 28128 & 83 ] & 0.9779 & 27.9575 & | 104.07 \\
\hline $\begin{array}{l}\text { Number of keys }=7, m=[257 \\
281283]\end{array}$ & 263 & 269 & 271 & 277 & -0.0067 & 8.0042 & 10296 \\
\hline $\begin{array}{l}\text { Number of keys }=8, m=[307 \\
337347 \quad 349]\end{array}$ & 311 & 313 & 317 & 331 & -0.00085318 & 8.0243 & 10248 \\
\hline 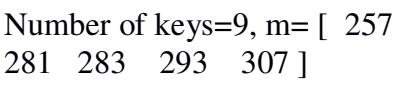 & 263 & 269 & 271 & 277 & 0.0013 & 8.7828 & 8606 \\
\hline 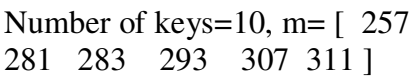 & 263 & 269 & 271 & 277 & 0.0024 & 8.7352 & 8700.7 \\
\hline
\end{tabular}

\section{Conclusion}

It is concluded from the result analysis of image encryption using CRT, that the encryption and decryption is optimal when the number of keys used are between 2 to 5 and the compression ratio is directly proportional to number keys used for encryption. Further it is observed that, if we increase the keys beyond the 5 , the decryption process is unable to produce a valid decrypted image. Hence, this paper concludes, that, the CRT not only be used for image encryption and it also provide compression as well.

\section{REFERENCES}

[1] A. Alfalou, C. Brosseau, Optical image compression and encryption methods, Advances in Optics and Photonics 1 (2009) 589-636.

[2] N. Akrout, R. Prost, R. Goutte, Image compression by vector quantization: a review focused on codebook generation, Image and Vision Computing 12 (1994) 627-637.

[3] A. Alkholidi, A. Alfalou, H. Hamam, A new approach for optical colored image compression using the JPEG standards, Signal Processing 87 (2007) 569-583.

[4] H.S. Soliman, M. Omari, A neural networks approach to image data compression, Applied Soft Computing 6 (2006) 258-271.

[5] A. Alfalou, A. Alkholidi, Implementation of an all-optical image compression architecture based on Fourier transform which will be the core principle in the realisation of DCT, Proceedings of the SPIE 5823 (2005) 183-190.

[6] M. Helsingius, P. Kuosmanen, J. Astola, Image compression using multiple transforms, Signal Processing: Image Communication 15 (2000) 513-529.

[7] M. Krinidis, N. Nikolaidis, I. Pitas, The discrete modal transform and its application to lossy image compression, Signal Processing: Image Communication 22 (2007) 480-504.

[8] X. Li, J. Knipe, H. Cheng, Image compression and encryption using tree structures, Pattern Recognition Letters 18 (1997) 1253-1259.

[9] S.S. Maniccam, N.G. Bourbakis, Lossless image compression and encryption using SCAN, Pattern Recognition 34 (2001) 1229-1245.

[10] O.Y. Lui, K.W. Wong, J. Chen, J. Zhou, Chaos-based joint compression and encryption algorithm for generating variable length ciphertext, Applied Soft Computing 12 (2012) 125-132.

[11] C.H. Yuen, K.W. Wong, A chaos-based joint image compression and encryption scheme using DCT and SHA-1, Applied Soft Computing 11 (2011) 5092-5098.

[12] Y. Zhao, B. Yuan, A hybrid image compression scheme combining block-based fractal coding and DCT, Signal Processing: Image Communication 8 (1996) 73-78.

[13] H.K.C. Chang, J.L. Liu, A linear quadtree compression scheme for image encryption, Signal Processing: Image Communication 10 (1997) 279-290.

[14] A. Alfalou, C. Brosseau, Exploiting root-mean-square time frequency structure for multiple-image optical compression and encryption, Optics Letters 35 (2010) 1914-1916. 
International Journal on Cybernetics \& Informatics (IJCI) Vol. 5, No. 4, August 2016

[15] H. Hermassi, R. Rhouma, S. Belghith, Joint compression and encryption using chaotically mutated Huffman trees, Communications in Nonlinear 15 (2010) 2987-2999.

[16] T.H. Chen, C.S. Wu, Compression-unimpaired batch-image encryption combining vector quantization and index compression, Information Sciences 180 (2010) 1690-1701.

[17] J.L. Liu, Efficient selective encryption for JPEG 2000 images using private initial table, Pattern Recognition 39 (2006) 1509-1517.

[18] Hegui Zhu, Cheng Zhao, Xiangde Zhang, A novel image encryption-compression scheme using ,hyper-chaos and Chinese remainder theorem, Signal Processing: Image Communication 28 (2013) 670-680

[19]Ding,D.Pei,A.Salomaa,ChineseRemainderTheorem.ApplicaionsinComputing,Coding,Cryptography,W orldScientificPublishing, 1996

[20] Ding C, Pei D, Salomaa A. Chinese remainder theorem: applications in computing, coding, cryptography. Singapore: World Scientific; 1999

[21] O.Goldreich,D.Ron,M.Sudan, Chinese remaindering with errors, IEEETrans .Inf.Theory 46(4)(2000)1330-1338.

[22] Johann GroBschadl: " The Chinese Remainder Theorem and its Application in a High-Speed RSA Crypto Chip." Proceedings of IEEE-2008.

[23] N. Syed Siraj Ahmed, R. Selvakumar, Akshay Taywade ,Public Key Cryptography Algorithm Using Binary Manipulation and Chinese Remainder Theorem, International Journal of Recent Technology and Engineering (IJRTE) ISSN: 2277-3878, Volume-2, Issue-5, November 2013

\section{AUTHOR}

Dr.O.Srinivasa Rao presently working as Associate professor of CSE, University College of Engineering, JNTUK, KAKINADA. His research field of interest is Computer Networks, Image Processing Network Security and Cryptography,

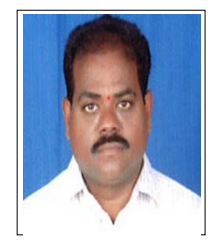

